\title{
PODER (DO) JUDICIÁRIO E “ZONAS DE AUTARQUIA”: A FORMA DIREITO NO MANDADO DE SEGURANCA COLETIVO DOS ESTAGIÁRIOS DO TJRS SOBRE O "RECESSO FORENSE"
}

\author{
Carlos Eduardo Pereira Siqueira* \\ José Rodrigo Rodriguez ${ }^{*}$
}

SUMÁRIO: Introdução; 2 A forma direito em disputa e as zonas de autarquia: debates do ms 70062879986; 3 Precariado, judiciário e distribuição do poder; $4 \mathrm{~A}$ centralidade do direito e a necessidade de uma esfera pública judiciária; 5 Conclusão; Referências.

RESUMO: Vinculado ao pensamento jurídico-crítico com raízes na "Escola de Frankfurt" e partindo das análises do jurista José Rodrigo Rodriguez, este trabalho buscará promover reflexões sobre a configuração do direito no caso particular do mandado de segurança coletivo processado e julgado pelo Tribunal de Justiça do Rio Grande do Sul (TJRS) a propósito da reivindicação de estagiários contra a suspensão do pagamento da remuneração durante o "recesso forense" de 2014/2015. Envolvido em tal proposta, este trabalho buscará promover reflexões sobre a configuração do direito no caso particular do mandado de segurança coletivo processado e julgado pelo Tribunal de Justiça do Rio Grande do Sul (TJRS) a propósito da reivindicação de estagiários contra a suspensão do pagamento da remuneração durante o "recesso forense" de 2014/2015. Para tanto, utilizou-se do método de estudo de caso, como via de pesquisa empírica apto a investigar os fatos e suas implicações e consequências relativos a um dado fenômeno devidamente delimitado. O problema estudado pode ser traduzido com as seguintes perguntas: como ocorreu a juridificação do conflito no mandado de segurança coletivo impetrado contra a suspensão do pagamento do "recesso forense" 2014/2015 do TJRS? De que modo as forças sociais envolvidas podem ser caracterizadas, considerando a decisão proferida? A abordagem terá em foco a necessidade de reformulações institucionais aptas a absorver inclusivamente as demandas sociais por meio da radicalização da democracia (RODRIGUEZ, 2009, 2013), o que se insere numa tarefa crítica de problematização das "zonas de autarquia”, categoria criada por Rodriguez e central ao trabalho. Ao final, as situações visualizadas apontaram, então, alguns modos de ser das zonas de autarquia e usos da falsa legalidade. Por outro lado, o debate público regulado democraticamente

\footnotetext{
Advogado. Mestre em Direito Público pela Universidade do Vale do Rio dos Sinos (UNISINOS). Pesquisador CAPES. Membro do Núcleo Direito e Democracia do Centro Brasileiro de Análise e Planejamento. Brasil. E-mail: cadupsiqueira@gmail.com

${ }^{* *}$ Doutor em Filosofia (linha Teoria do Direito e do Estado) pela Universidade Estadual de Campinas. Professor do PPG (Mestrado e Doutorado) da UNISINOS e Pesquisador Permanente do CEBRAP ligado ao Núcleo Direito e Democracia. Brasil.
} 
permite que posições até agora contra-hegemônicas sejam defendidas em nome da emancipação social. A "luta por direitos na democracia" é a chave para evitar retrocessos.

PALAVRAS-CHAVE: Zonas de autarquia; Esfera pública.

\section{POWER OF THE JUDGE AND "AUTARCHY ZONES": DIRECT FORM IN THE COLLECTIVE INJUNCTION OF TJRS TRAINEES ON "COURT VACATION"}

ABSTRACT: Current analysis is based on the juridical and critical thought rooted in the Frankfurt School and on the investigation of the jurist José Rodrigo Rodriguez. The paper discusses the configuration of law on the collective injunction processed and judged by the Court of the state of Rio Grande do Sul (TJRS) on the vindication of trainees against the suspended payment during the 2014/2015 court vacation. The case study method was employed for an empirical research within the investigation of facts, their implications and relative consequences to a duly limited phenomenon. The issue may be resumed in the following questions: How did the judicialization of the conflict in the collective injunction occur against the suspension of payment for the 2014/2015 court vacation of the TJRS? How may social forces involved be characterized within the context of the decision? Current approach requires proper institutional reformulations to absorb social demands through the radicalization of democracy (RODRIGUEZ, 2009, 2013). It is thus inserted within the critical task of the problematization of the 'autarchy zones', a category formulated by Rodriguez and basic in current paper. Situations indicate some modes of existence of the autarchy zones and the employment of false legality. On the other hand, the democratically governed public debate permits that the up-till-now contra-hegemonic positions may be defended in the name of social emancipation. The 'struggle for rights in democracy' is the key to avoid backtracking.

KEY WORDS: Autarchy Zones; Public Sphere.

\section{PODER (DEL) JUDICIARIO Y “ZONAS DE AUTARQUÍA”: LA FORMA DERECHO EN EL MANDADO DE SEGURANZA COLECTIVO DE LOS PRACTICANTES DEL TJRS SOBRE EL "RECESO FORENSE"}

RESUMEN: Vinculado al pensamiento jurídico-crítico con raíces en la "Escuela de Frankfurt" y partiendo de los análisis del jurista José Rodrigo Rodríguez, en este estudio se buscará promover reflexiones sobre la configuración del derecho en el caso particular del mandado de seguranza colectivo procesado y juzgado por el Tribunal 
de Justicia del Rio Grande do Sul (TJRS) a propósito de la reivindicación de aprendices contra la suspensión del pago de la remuneración durante el "receso forense" de 2014/2015. Involucrado en tal propuesta, en este estudio se buscará promover reflexiones sobre la configuración del derecho en el caso particular del mandado de seguranza colectivo procesado y juzgado por el Tribunal de Justicia de Rio Grande do Sul (TJRS) a propósito da reivindicaciones de practicantes contra la suspensión del pago de la remuneración durante el "receso forense" de 2014/2015. Para tanto, se utilizó del método de estudio de caso, como vía de investigación empírica apto a investigar los hechos y sus implicaciones y consecuencias relativos a un dado fenómeno debidamente delimitado. El problema estudiado puede ser traducido con las siguientes preguntas: ¿cómo sucedió la "juridificación" del conflicto en el mandado de seguranza colectivo impetrado contra la suspensión del pago del "receso forense" 2014/2015 do TJRS? ¿De qué modo las fuerzas sociales implicadas pueden ser caracterizadas, considerando la decisión proferida? El abordaje tendrá en enfoque la necesidad de reformulaciones institucionales aptas a absorber inclusivamente las demandas sociales por intermedio de la radicalización de la democracia (RODRIGUEZ, 2009, 2013), lo que se insiere en una tarea crítica de problematización de las "zonas de autarquía", categoría creada por Rodríguez y central al trabajo. Al final, las situaciones visualizadas apuntaron, entonces, algunos modos de ser de las zonas de autarquía y usos de la falsa legalidad. Por otro lado, el debate público regulado democráticamente permite que posiciones hasta el momento contra-hegemónicas sean defendidas en nombre de la emancipación social. La "lucha por derechos en la democracia" es la clave para evitar un paso hacia atrás.

PALABRAS CLAVE: Zonas de autarquía; Esfera pública.

\section{INTRODUÇÃO}

$\mathrm{Na}$ atualidade, é cada vez mais frequente que reivindicações sociais por direitos, ou melhor, pelo reconhecimento e salvaguarda institucional de interesses e necessidades, resultem em demandas judiciais. Vários vieses são lançados sobre esse fenômeno, tanto para explicá-lo quanto para "resolvê-lo". Particularmente, os modelos críticos ${ }^{03}$, que têm como tarefa de pesquisa o debate sobre o direito e/ou a integração social mediada pela forma direito, voltam-se para os processos de juridifi-

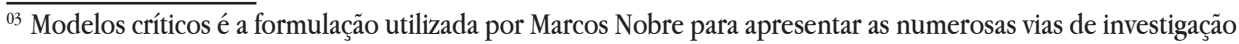
crítica caracterizada pela análise do estado de coisas onde a sociedade está imbricada e as possibilidades de emancipação social. Vastas são as maneiras de desenvolver pesquisa crítica porque, segundo ele, "a Teoria Crítica só tem vida e interesse se for permanentemente reformulada e repensada em vista de novas condições históricas." (Nobre, 2015, p. 18)
} 
cação ${ }^{04}$ a fim de elaborar diagnósticos do tempo presente, voltando-se aos potenciais emancipatórios subjacentes aos conflitos.

Nesse contexto de elaboração crítica do saber direcionada a uma práxis de emancipação humana, nem de longe vinculada exclusivamente ao direito (até por sua característica basilar de interdisciplinaridade), há uma corrente conectada aos estudos desenvolvidos a partir da primeira metade do século XX no Instituto de Pesquisa Social, fundado como centro de pesquisas da Universidade de Frankfurt. No Brasil, destaca-se o trabalho do jurista José Rodrigo Rodriguez, para quem

o papel do pensamento crítico não é desvendar qual seja a "natureza" do direito de forma definitiva, mas dar conta de suas diversas configurações ao longo da história sem naturalizar seus conceitos. E sem perder de vista os interesses em conflito que lutam para se expressar no direito e defendem visóes diferentes do que ele é e deve ser. ${ }^{5}$

Envolvido em tal proposta, este trabalho buscará promover reflexões sobre a configuração do direito no caso particular do mandado de segurança coletivo processado e julgado pelo Tribunal de Justiça do Rio Grande do Sul (TJRS) a propósito da reivindicação de estagiários contra a suspensão do pagamento da remuneração durante o "recesso forense" de 2014/2015. Para tanto, utilizou-se do método de estudo de caso, como via de pesquisa empírica apto a investigar os fatos, com suas implicações e consequências, relativos a um dado fenômeno devidamente delimitado.

Como dito, o interesse em pesquisar o contexto da citada manifestação de estagiárias e estagiários levou ao recorte metodológico voltado especificamente para a análise do mandado de segurança impetrado pelas organizações estudantis que representaram a categoria interessada. A partir daí, buscou-se, por meio da análise das petições, despachos, decisões, votos, acórdãos e outros documentos oficiais, compreender os sentidos atribuídos ao direito e aos direitos disputados judicialmente em face do próprio judiciário. Eventualmente, dados colhidos em entrevistas utilizadas pelo grupo de pesquisa a partir do qual este artigo foi desenvolvido serão mencionados para contextualizar ou melhor explicitar alguns elementos.

Em breve síntese, ao praticar pela segunda vez o "recesso forense" de fim de ano - historicamente observado na justiça federal e em Tribunais Superiores, nos

\footnotetext{
${ }^{04}$ Para alguns apontamentos sobre o complexo fenômeno da juridificação, ver Teubner (1988).

${ }^{05}$ RODRIGUEZ, José Rodrigo. Como decidem as cortes?: para uma crítica do direito (brasileiro). Rio de Janeiro: FGV, 2013, p. 18.
} 
termos do art. 62 da lei n. 5.010 de 1966, e já observado por outros tribunais das jurisdições estaduais ${ }^{06}$ - a administração do TJRS instituiu o corte do pagamento desses dias não trabalhados em relação aos estagiários e às estagiárias, provocando manifestações públicas, requerimentos administrativos e impetração do mandado de segurança (MS) tombado sob o n. 7006287986. Como essa categoria de trabalhadores, representada na ação por diversos centros/diretórios acadêmicos de diferentes instituições de ensino superior do Rio Grande do Sul, abordou o que entendia ser seus direitos e, por outro lado, que análise e resposta qualificadas como jurídicas foram oferecidas ao caso é o que importa problematizar.

Trata-se, aqui, de análise parcial pertencente a uma pesquisa mais ampla intitulada "Luta por direitos: a paralisação dos estagiários e das estagiárias do Tribunal de Justiça do Rio Grande do Sul de 2014”. Na presente ocasião, o problema estudado pode ser traduzido com as seguintes perguntas: como ocorreu a juridificação do conflito no mandado de segurança coletivo impetrado contra a suspensão do pagamento do "recesso forense" 2014/2015 do TJRS? De que modo as forças sociais envolvidas podem ser caracterizadas, considerando a decisão proferida?

A abordagem terá em foco a necessidade de reformulações institucionais aptas a absorver inclusivamente as demandas sociais por meio da radicalização da democracia $^{07}$. Para tanto, considerará a necessidade de controle da atuação estatal ora identificada pelo poder judiciário e a mediação dos grupos sociais em conflito como papel de um direito democraticamente instituído. Assim, ter-se-á como objetivo contribuir para a formulação do judiciário enquanto esfera pública aberta à "luta por direitos", para além do exercício da função "técnica" enquanto sua manifestação do poder estatal ${ }^{08}$.

O caso em apreço guarda especial relevância pelo fato de que o judiciário não se apresenta como externo à relação jurídica debatida em juízo por meio do MS n. 7006287986. São atos da administração do TJRS, editados por magistrados que o compõem, o foco do conflito, aos quais se atribuíram as qualidades de ilegais e abusivos na petição dos autores do mandado de segurança. Logo, sob o ponto de vista institucional, as autoridades do tribunal são, ao mesmo tempo, julgados e

\footnotetext{
${ }^{06}$ Autorização para a extensão do "recesso" ao âmbito estadual contida na Resolução n. 8/2005 do Conselho Nacional de Justiça.

${ }^{07}$ Ver RODRIGUEZ, 2009, 2013.

${ }^{08}$ Há muito alguns juristas vêm criticando a apresentação do judiciário enquanto mero exercício da "técnica jurídica", sendo esta uma formulação disposta a favor dos interesses da elite dominante. Por todos, ver obra coletiva organizada por José Eduardo Faria (1997).
} 
julgadores, já que, a rigor, a conduta é atribuída ao ente e não à pessoa ${ }^{09}$. Mesmo que incidam regras de impedimento sobre alguns, não deixam de ocupar o cargo, estar na sessão de julgamento enquanto magistrado (e não como jurisdicionado) e exercer influência/poder sobre a estrutura a que se submetem os demais juízes, servidores e estagiários.

Apesar de não se ter conhecimento de estudos sistemáticos sobre esse problema, não será concebida uma teoria a respeito das características da jurisdição pátria e das formas de controlá-la. As análises levarão em conta as descobertas de Rodriguez, notadamente em seu "Como decidem as cortes?", ao demonstrar a racionalidade jurisdicional pátria como personalista, opinativa e autárquica, segundo sua formulação de "zona de autarquia" como indevida dispensa de que os poderosos justifiquem "racionalmente suas posições de domínio ao excluir determinados conceitos jurídicos e desenhos institucionais do debate público" 10 .

Portanto, para compreender criticamente o papel do direito na ação judicial referida, discutir os limites da ordem institucional configurada no caso e suscitar vias democráticas de resolução da questão judicializada, serão importados conceitos que viabilizem o tratamento das peculiaridades dos fatos apreciados sem perder de vista condicionantes estruturais. Para o intento, dividiu-se o texto em três partes: na primeira, serão discutidos os conceitos de direito disputados e as respectivas racionalidades emergentes; em seguida, o foco será voltado para a posição sociopolítica dos atores envolvidos e para a jurisdição como polo de distribuição de poder no processo judicial estudado; por fim, será problematizado tanto a centralidade do direito e do judiciário para a integração social quanto à necessidade de abertura do judiciário para a esfera pública como tarefa democrática rumo à emancipação humana.

\section{A FORMA DIREITO EM DISPUTA E AS ZONAS DE AUTARQUIA: DEBATES DO MS 70062879986}

De acordo com as entrevistas realizadas no âmbito do mencionado projeto de pesquisa do qual este artigo é parte, o Tribunal de Justiça do Rio Grande do

\footnotetext{
${ }^{99}$ Não é objetivo do trabalho retratar a atribuição de responsabilidade na administração. Sendo assim, utiliza-se a posição dogmática tradicional de que a administração pública, incluindo a judiciária, é regida pela impessoalidade, por ser comando constitucional disposto expressamente no art. 37 da Constituição vigente.

${ }^{10}$ RODRIGUEZ, José Rodrigo. Como decidem as cortes?: para uma crítica do direito (brasileiro). Rio de Janeiro: FGV, 2013, p. 21)
} 
Sul comunicou via informativo eletrônico que estagiários e estagiárias não seriam remunerados durante o recesso 2014/2015. Num texto bastante sucinto da lavra do $3^{\circ}$ vice-presidente, informou-se que "durante o período de recesso (de 20/12/2014 a 06/01/2015), não haverá pagamento aos estagiários", atribuindo a decisão a questionamento formulado pelo Tribunal de Contas do Estado (TCE), de modo que "a negativa de pagamento independe da atual Administração".

A imediata insatisfação da categoria atingida pela medida fez com que o tema fosse levado ao Centro Acadêmico de Estudantes de Direito da Universidade do Vale do Rio dos Sinos (CAED). Naquele momento, os dirigentes estudantis mobilizaram-se para participar do ato dos servidores do judiciário articulado para 07/11/2014, a fim de convocar um ato próprio para o dia 10/11/2014. Como não se pretende proceder ao exame minucioso dos acontecimentos, importa considerar que cerca de 300 manifestantes reuniram-se à frente do TJRS no dia marcado, protocolaram requerimento administrativo e foram recebidos pelo $3^{\circ}$ vice-presidente, que, além de responsabilizar o TCE, diferenciou hierarquicamente estagiários de servidores e magistrados ${ }^{11}$.

Não satisfeitos com as respostas, novo ato fora agendado para 13/11/2014, que começou na frente do TJ e foi até o TCE, onde protocolaram novo pedido de explicações e foram recebidos por representantes do órgão de contas. Cerca de 600 pessoas, segundo estimativa de alguns participantes, participaram da mobilização, que obteve como resposta da Corte de Contas a mensagem de que "não se localizou nenhum Relatório de Auditoria, referente à fiscalização levada a efeito no Tribunal de Justiça do Estado do Rio Grande do Sul, que contivesse apontamento relativo à matéria mencionada no pedido". Diante do conflito de informações e da posterior edição pela "Comissão de Supervisão de Estágio do TJ/RS" de regulamento específico sobre a ausência de remuneração durante o "recesso", resolveu-se impetrar mandado de segurança coletivo, cujos autores foram o CAED e pelo menos outras sete entidades de representação estudantil. Segundo relatos, resolveu-se ingressar com a ação na porta do TCE, logo após a conversa com integrantes do ente.

Se os estudantes apostaram na proteção do direito contra o que lhes parecia autoritarismo, a administração do TJRS buscou se eximir da responsabilidade pela decisão política de não efetuar o pagamento de estagiários entre os dias 20/12/2014 e 06/01/2015. A decisão tomada coletivamente pelo tribunal só veio à tona no curso

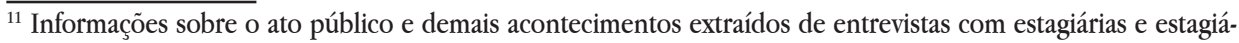
rios.
} 
do processo, quando o $3^{\circ}$ vice-presidente prestou suas informações, oportunidade em que deu conhecimento da decisão tomada já em 11/09/2014 pelo próprio tribunal, sem qualquer referência ao TCE. A partir desse ponto, percebem-se dois modos de encarar a institucionalidade: o dos membros do ente público e dos estagiários.

O judiciário gaúcho não promoveu uma comunicação clara quanto à medida adotada. Preferiu eximir-se de qualquer ônus/crítica por parte dos estagiários e manteve em sigilo o efetivo procedimento seguido para chegar àquele resultado. Antes e pior que isso, não incluiu a categoria atingida na tomada de decisão, inviabilizando a interação de diferentes perspectivas antes de exercer seu poder de mando. Uma zona de autarquia havia sido criada, considerando a falta de justificativa e o déficit democrático da postura oficial.

Para combater o ato autárquico, lançou-se mão de mandado de segurança, ou em outros termos, socorreu-se na jurisdição. Nesta perspectiva, foram aventados os princípios constitucionais da igualdade/isonomia, razoabilidade e mesmo a legalidade, além dos objetivos e fundamentos constitucionalmente estabelecidos para o Estado democrático de Direito brasileiro. Dispositivos legais e resoluções do tribunal também foram mencionados. Vale ressaltar que a judicialização só ocorreu depois do protocolo de dois requerimentos administrativos, um no TJRS e outro no TCE. Para a categoria, um Estado que, segundo a Constituição da República, é fundado na dignidade humana e no valor social do trabalho e voltado para a construção de uma sociedade livre, justa e solidária, vedada distinção de qualquer natureza, que ainda garante o acesso à informação e a participação popular, não poderia admitir a suspensão do pagamento tal qual realizada. Como se vê, o corte foi percebido em sua faceta plenamente jurídica, levando à juridificação da demanda por pagamento.

Por seu turno, o judiciário entendeu que a lei regente da relação de estágio - lei n. 11.788/08, denominada Lei do Estágio - apenas se refere ao pagamento dos dias trabalhados. Mencionada ainda o caráter contratual (não trabalhista) da relação de estágio, pelo que não se poderia falar em equiparação com as outras categorias de trabalhadores. Respalda-se na supremacia da legalidade para a atuação administrativa, de modo que a falta de previsão para remuneração de dias não trabalhados inviabilizaria o pagamento. Argumenta que o pagamento realizado no ano anterior não impede a regularização no ano seguinte e arremata com a necessidade de se levar em conta advertência informalmente realizada pelo Tribunal de Contas, frisando o apego à legalidade. Transparece o uso do conceito técnico de direito, segundo o 
qual estaria ele apenas sujeito às unívocas disposições legais, sendo inquestionáveis os atos de observância legal. Cumprir a lei seria tarefa simples, já que seu sentido estaria dado nos conceitos jurídico-formais previamente estabelecidos. Não há, pois, sob esse ponto de vista, necessidade de reconstrução dos institutos, mas apenas sua aplicação objetiva.

De antemão, cumprindo o dever crítico de reconstrução do instituto, observa-se erro dogmático da decisão proferida. O tão debatido "recesso", adotado por extensão da lei n. 5.010/1966, refere-se à existência de feriado, não de dias fora do calendário forense, até porque todo serviço público essencial é caracterizado por ser ininterrupto. A disposição diz que "Além dos fixados em lei, serão feriados na Justiça Federal, inclusive nos Tribunais Superiores: I - os dias compreendidos entre 20 de dezembro e 6 de janeiro, inclusive;" (art. 62). Segundo o dicionário Michaelis, feriado significa "Consagrado ao repouso. $\boldsymbol{s} \boldsymbol{m}$ Dia ou tempo em que se suspende o trabalho para descanso por prescrição civil ou religiosa; férias de um dia." ${ }^{2}$. Assim, não pode ser tratado como encerramento da atividade jurisdicional com posterior reinício, com alguma espécie de suspensão não remunerada do contrato de estágio, com cessação das obrigações pactuadas.

Uma vez que a lei se refere em feriado, é possível tratá-lo de maneira diversa sem uma justificativa jurídico-racional? Outros feriados do ano implicam corte na remuneração? Parece que a resposta para ambas as perguntas é não, a colocar em xeque a posição do tribunal. Ademais, se a retribuição pelo trabalho é obrigatória e mensal em forma de bolsa (art. 12 da Lei do Estágio), não se pode pagar à razão de dias úteis, sob pena de estabelecer remuneração diária. O dever de pagar bolsa, de acordo com a lei, ocorre pelo caráter de estágio não obrigatório. Ao mesmo tempo, a bolsa é unidade fixa de pagamento, não podendo ser calculada em função dos dias úteis de cada mês. Sem entrar na discussão sobre a aplicabilidade ou não da CLT a esse tipo de relação, deve-se utilizar sua qualificação de feriado como dia vedado ao trabalho (art. 70) apenas por falta de outro que o substitua. É simples apontamento de que se trata de dia de descanso a beneficiar o trabalhador/estagiário, jamais a prejudicá-lo (com corte de pagamento). Para além disso, como estágio é "ato educativo escolar supervisionado" (art. 10 ${ }^{\circ}$, Lei n. 11.788/2008) e não prestação de força de trabalho/mão-de-obra em favor do empregador pura e simplesmente (pelo menos em seara legal), foge a seu pressuposto básico a subtração de valores da bolsa por força de feriado, momento em que trabalhar não é opção disponível.

\footnotetext{
${ }^{12}$ MICHAELIS DICIONÁRIO DE PORTUGUÊS ONLINE. Feriado. Disponível em: < http://michaelis.uol.com.br/ moderno/portugues/index.php?lingua $=$ portugues-portugues\&palavra $=$ feriado $>$. Acesso em: 10 fev. 2016.
} 
Por essa consideração lógico-dogmática, parece ter havido "fuga do direito"13 por parte do judiciário gaúcho. Isso porque, no entender de Rodriguez (com quem se concorda), a forma direito não é uma roupagem formal a atos de poder. É uma garantia democrática de estabelecimento de mecanismos de participação e controle da regulação pela sociedade. Falar em nome da legalidade, como feito na decisão proferida, não é o mesmo que guardar reverência à forma direito. Conforme reflete o jurista,

Num Estado Democrático, os cidadãos podem influenciar a regulação, pois a forma direito é sempre inclusiva de novas demandas. A vigência da forma direito não é um dado natural; depende de comprovação empírica. Não basta postular sua existência ou sua inexistência para que a análise que se segue se justifique. ${ }^{14}$

Nesse sentido, estagiários reivindicaram a forma direito, inclusive quanto a pouco observada participação direta na formulação de políticas. Invocaram o art. $10 \mathrm{da}$ Constituição, que apregoa que "É assegurada a participação dos trabalhadores e empregadores nos colegiados dos órgãos públicos em que seus interesses profissionais ou previdenciários sejam objeto de discussão e deliberação.". Esse argumento foi afastado pela alegação de que o estágio é relação contratual, sem maiores justificativas a respeito de sua não incidência nessa circunstância, bem como sem considerar a carga principiológica da previsão. Também por isso, é possível acusar o TJRS de afastamento da forma direito e consequente assentamento de uma zona de autarquia.

Em verdade, tudo indica que o TJRS utilizou o formalismo jurídico (que não é o mesmo que a forma direito) para revestir de legalidade as escolhas feitas quanto à gestão dos recursos humanos. Por sua explicação, o "recesso forense" não equivale às férias do art. 13 da lei do estágio, o que afastaria o dever de pagar aqueles dias não trabalhados, por falta de imposição legal (tendo em vista a necessidade de lei para a atuação administrativa). Ocorre que a legalidade a que se refere o julgado tem vínculo com o que Rodriguez denominou "falsa legalidade" (ou legalidade discriminatória), que é a "produção de normas aparentemente universais, mas que são efetivamente postas a serviço de interesses parciais, por exemplo, atingir apenas a

${ }^{13}$ RODRIGUEZ, José Rodrigo. Fuga do direito: um estudo sobre o direito contemporâneo a partir de Franz Neumann. São Paulo: Saraiva, 2009.

${ }^{14}$ RODRIGUEZ, José Rodrigo. Fuga do direito: um estudo sobre o direito contemporâneo a partir de Franz Neumann. São Paulo: Saraiva, 2009, p. 132. 
determinados grupos sociais e não outros"15. Isso porque a norma produzida pelo judiciário diante do caso concreto não racionaliza ${ }^{16} \mathrm{o}$ direito aplicado, inviabilizando a universalização da resposta dada, pois, por exemplo, a decisão não pode ser estendida aos demais casos de feriado, não analisa o instituto do estágio nem o da respectiva bolsa e não enfrenta argumentos como o do princípio da igualdade. Contudo, possui aparência de conformidade ao sistema jurídico, vez que proferida por autoridade competente, por meio de trâmite processual tido como normal e com decisão expondo o ponto de vista do julgador (mesmo que isso não resulte em efetiva fundamentação).

Sobre a igualdade, interessa destacar relevante fato. Por que magistrados e servidores recebem normalmente durante o "recesso forense" e estagiários não? Apenas a "natureza contratual" do vínculo é suficiente para justificar isso? Se todos desempenham trabalho dirigido à prestação jurisdicional, há critério para discriminar o estágio? Tais perguntas precisavam ser respondidas pelo tribunal. Apesar de não haver dúvidas de que ocorrera tratamento diferenciado, não se expôs a fundamentação jurídica para tanto. Porém, como o argumento de autoridade é característica de nossa jurisdição, prevalece como legal aquilo que o órgão julgador assim o qualifica. No mesmo sentido, reflete-se a "lógica do parecer", em que se "recolhe o material jurisprudencial e doutrinário e os devidos títulos legais unicamente em função da tese a ser defendida: não recolhe todo o material disponível, mas tão-só a porção dele que vem ao encontro daquela tese" ${ }^{17}$.

Por sua vez, o mandado de segurança ora analisado não se relaciona com essas categorias críticas do direito simplesmente por refletir características padronizadas do judiciário. A posição dos atores envolvidos e o papel desempenhado pela jurisdição no caso levantam outros aspectos que precisam ser estudados.

\footnotetext{
${ }^{15}$ NOBRE, Marcos. Introdução. In: NOBRE, Marcos. Curso livre de Teoria Crítica. 3. edição. 2. reimpressão. Campinas: Papirus, 2015, p. 141.

${ }^{16} \mathrm{Na}$ esteira de Neumann (2013), deve-se esclarecer que "Quando dizemos que o Estado e o direito são fundados secular e racionalmente, queremos com isso dizer apenas que o Estado e o direito não são criações de Deus nem das instituições do demônio; que eles não são nem instituições supra-humanas nem subumanas, mas que eles são simplesmente instituições humanas originadas da vontade ou da carência dos homens" (p. 73), devendo, assim, estar em constante processo de fundamentação de sua estrutura, institutos e funcionamento, de acordo com critérios democráticos.

${ }^{17}$ NOBRE, Marcos. Apontamentos sobre a pesquisa em direito no Brasil. Novos Estudos, número 66, p. 145-154, julho de 2003, p. 150. Disponível em: < http://novosestudos.uol.com.br/v1/contents/view/1079>. Acesso em: 21 jan. 2016.
} 


\section{PRECARIADO, JUDICIÁRIO E DISTRIBUIÇÃO DO PODER}

Guy Standing, ao analisar a organização social diante das contemporâneas estruturas econômicas, identifica modos de vida precários, estabelecendo algumas características do que denomina "precariado", enquanto classe inserida em relações de insegurança permanente, vulnerabilidade, flexibilidade e desagregação ${ }^{18}$. Estagiários e estagiárias, incluídos nessa ordem de precariedade, compõem um grupo social sujeito a condições de trabalho de exploração em nível mais degradante que a classe trabalhadora com emprego formal nos moldes clássicos do proletariado. Logo, estão mais propensos a sofrer violações em seus direitos, ou seja, estão submetidos à maior probabilidade de terem suas necessidades e interesses rejeitados/ ignorados pelo "direito" oficial. Segundo Standing,

O precariado tem características de classe. Consiste em pessoas que têm relações de confiança mínima com o capital e o Estado, o que as torna completamente diferentes do assalariado. E ela não tem nenhuma das relações de contrato social do proletariado, por meio das quais as garantias de trabalho são fornecidas em troca de subordinação e eventual lealdade, o acordo tácito que serve de base para os Estados de bem-estar social. ${ }^{19}$

Na prática, eles [os estágios] são usados por muitos empregadores como um meio de obter trabalho dispensável barato. ${ }^{20}$

Os estágios são uma ameaça para os jovens que estão no precariado e em torno dele. Mesmo que haja um pagamento, os estagiários estão fazendo um trabalho barato sem perspectiva de progresso, que pressiona para baixo os salários e as oportunidades de outros que normalmente poderiam ser empregados. ${ }^{21}$

O estágio, enquanto vínculo precário de trabalho, disponibiliza poucos direitos. A lei n. 11788/2008 afasta a atuação de estagiários e de estagiárias do vínculo

\footnotetext{
${ }^{18}$ Não é de se ignorar o debate sobre as características do "precariado" e sobre sua configuração ou não como uma classe própria ou "para si". No Brasil, Ruy Braga (2012) estabelece essa discussão, apresentando divergências em relação a Standing. Outrossim, por não ser tema específico deste texto, não serão feitas reflexões a respeito do assunto, focando na convergência de que a pressão econômica atual sobre os trabalhadores e trabalhadoras tem produzido modos de vida cuja precarização atinge níveis extremos. Para Braga, "identificamos o precariado com a fração mais mal paga e explorada do proletariado urbano e dos trabalhadores agrícolas, excluídos a população pauperizada e o lumpemproletariado, por considerá-la própria à reprodução do capitalismo periférico" (2012, p. 19). Por se concordar com a descrição de Standing quanto aos vínculos de trabalho do precariado, ponto que mais interessa no momento, será adotada a perspectiva dele em detrimento das demais.

${ }^{19}$ STANDING, Guy. O precariado: a nova classe perigosa. 1. edição. 1. reimpressão. Belo Horizonte: Autêntica Editora, 2014, p. 25.

${ }^{20}$ STANDING, Guy. O precariado: a nova classe perigosa. 1. edição. 1. reimpressão. Belo Horizonte: Autêntica Editora, 2014, p. 120.

${ }^{21}$ STANDING, Guy. O precariado: a nova classe perigosa. 1. edição. 1. reimpressão. Belo Horizonte: Autêntica Editora, 2014, p. 122.
} 
empregatício (art. $3^{\circ}$ ), o que desobriga aquele que é beneficiado com o trabalho quanto a deveres trabalhistas. Criam-se vínculos efêmeros entre as partes, dada à transitoriedade da relação (o art. 11 estipula o máximo de 02 anos para o estágio), além de não se impor o pagamento de salário mínimo, $13^{\circ}$ salário, verbas previdenciárias, dentre outros direitos laborais. Para piorar, segundo relatos de entrevistas, não há associação coletiva da categoria, e estagiários e estagiárias estão submetidos ao poder de comando direto de seus superiores, havendo pouca organicidade quanto à dinâmica de trabalho no âmbito do TJRS, já que cada magistrado possui seu método de trabalho.

É de se acrescentar o forte indício de substituição de mão de obra por aumento no número de estagiários. Entrevistas chegam a anunciar que muitas varas são compostas majoritariamente por esses trabalhadores, havendo casos em que a saída de um servidor efetivo foi imediatamente substituída por contratação de estagiário. Isso aumenta a precarização do trabalho dentro do tribunal como um todo e reforça a exploração da força laborativa de um grupo mais vulnerável. No caso concreto, a "natureza" do liame serviu até para justificar a exclusão da categoria do debate sobre as políticas de recursos humanos além de "respaldar" tratamento discriminatório, considerando que, apenas, estagiários e estagiárias sofreram corte por ocasião do "recesso".

Corroborando a suspeita de substituição de mão de obra, deve-se considerar que, de acordo com dados publicados no sítio eletrônico do TJRS, 27,6\% da força de trabalho da corte ( $1^{\circ}$ e $2^{\circ}$ graus) era formada por estagiários e estagiárias, considerando a quantidade total de magistrados(as), servidores(as) e estagiários(as). Apesar de o art. 17 da lei n. 11788/2008, que regula o número máximo de estagiários por entidade, não se aplicar a estágio de nível superior (por previsão expressa do $\S$ $4^{\circ}$ ), é interessante perceber a repercussão da grande representatividade dos vínculos de estágio. Mesmo a doutrina mais tradicional considera que

A ideia do número máximo de estagiários tem por objetivo evitar a transformação de postos de trabalho em estágio para não ter vínculo trabalhista e diminuir encargos. Visa evitar que a empresa substitua mão de obra permanente por estagiários, com custo mais barato. ${ }^{22}$

Em assim sendo, mesmo não se aplicando o limite máximo de $20 \%$ de estagiários (art. 17, IV), o papel do estágio de mão de obra de fácil exploração parece

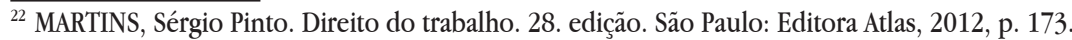


se evidenciar no TJRS. Até porque, de acordo com algumas entrevistas, a própria obrigação legal atribuída à instituição de ensino de acompanhar efetivamente as atividades desempenhadas pelo(a) estudante-estagiário(a) prevista no $\S 1^{\circ}$ do art. $3^{\circ}$ da lei n. 11.788/2008 não é devidamente cumprida. O que estudantes terminam aprendendo é a praxe forense, muitas vezes carregada de vícios cotidianos, de fazeres de um judiciário "opinativo" ${ }^{234}$ a atuar segundo o já referido modelo do parecer.

Essas considerações são importantes porque mostram como a especial posição subalternizada de estagiários e estagiárias está atrelada a obstáculos estruturais que de fato the foram impostos pela administração do TJRS. Poder-se-ia dizer que está havendo ampliação das zonas de autarquia, porque a regulação pública está cedendo em favor da privada. Relações estão sendo excluídas do controle estatal e empurradas para o âmbito contratual, mesmo quando órgãos públicos sejam interessados. Assim, são criados artifícios para formalizar/institucionalizar negativa de direitos e expulsar sujeitos do espaço público, transformando o "direito" estatal em mera técnica à disposição dos poderes econômico e político.

Nessa condição, se adotarmos a compreensão de Neumann de que o Estado é constituído pela relação tensa e complexa entre soberania e Império do Direito (2013, p. 38), teria havido um desequilíbrio entre esses elementos para fazer preponderar o poder soberano. Para o autor, "toda instituição é chamada soberana quando possui poder não delegado e ilimitado para emitir normas gerais e comandos (decisões) individuais" ${ }^{25}$. No exercício desse poder, modernamente, costuma-se dividir a atuação estatal em três funções básicas: legislativo, executivo e judiciário. Com isso, haveria mecanismos de controle com o objetivo de evitar o acúmulo de poder por um órgão ou pessoa, em especial a partir da formulação clássica de tripartição de poderes de Montesquieu. Porém, os magistrados que compõem o TJRS, sobretudo sua cúpula, detiveram triplo mecanismo de expressar seu poder soberano.

Em primeiro lugar, editaram a norma geral aplicável ao pagamento da contraprestação do trabalho de estagiários durante o feriado de fim de ano. Criaram, por deliberação da "Comissão de Supervisão de Estágio", o regulamento que estabelecia a paralisação da corte entre 20/12 e 06/01, prevendo o corte na bolsa de estágio. Em

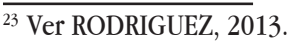

${ }^{24}$ Segundo José R. Rodriguez, “a jurisdição opinativa não decide em função de argumentos, não é constrangida por eles, posto que, como veremos, os fundamentos de suas decisões sempre ficam em aberto. (...). O resultado disso é um manancial de argumentos, doutrinadores, leis, casos etc., que torna praticamente impossível reconstruir a argumentação do tribunal de maneira racional e unificada." (idem, 2013, p. 82).

${ }^{25}$ NEUMANN, Franz. O Império do Direito: Teoria política e sistema jurídico na sociedade moderna. São Paulo: Quartier Latin, 2013, p. 69.
} 
segundo ato, diante da provocação jurisdicional levada a cabo pela impetração do mandado de segurança, praticou seu poder típico de resolução de contenda judicial, ratificando em liminar (e, posteriormente, no acórdão transitado em julgado) a determinação regulamentar. No terceiro momento, promoveu autoexecutoriamente a implementação das medidas, realizando a previsão no plano fático-social. Diante desse acúmulo de todo o conteúdo da soberania, o judiciário foi, na prática, instância revisora de seu próprio ato. Para questionar a conduta do tribunal, o mesmo tribunal foi provocado, marcando a presença excessiva do poder soberano e tímida do direito. Ainda segundo Neumann,

Em sentido sociológico, uma instituição é chamada soberana se possui não apenas direitos jurídicos desse tipo [poder não delegado e ilimitado], mas também se tem a habilidade para manter as normas e comandos emitidos por meio desses direitos. Portanto, num sentido sociológico de soberania está incluído um elemento tanto do direito quanto do poder. ${ }^{26}$

Mesmo que, na complexidade da relação entre soberania e Império do Direito, a atuação estatal tenha que ser revestida de juridicidade, o poder de subordinar pode apenas ter reflexo formal na legislação. Isso porque, em circunstâncias como a do MS em estudo, será jurídico aquilo que o tribunal assim o declara. Logo, não se pode falar na observância da forma direito, esta identificada com a inclusão de demandas sociais e influência popular nas esferas de comando. Então, pode-se falar em postura oficial autoritária, já que o direito cedeu em face do poder.

Prova disso são os atos processuais observados no mandado de segurança. Não sob o ponto de vista técnico-procedimental, mas sob a ótica da efetiva construção discursivo-argumentativa da resposta judicial é que se analisa a questão. Isso porque, processualmente e à primeira vista, nada infirma a competência do Órgão Especial do TJRS, enquanto colegiado de mais alta hierarquia, para julgar o ato puro e simples do presidente e das três vice-presidências. Contudo, a imputação de ato ilegal à direção do tribunal gerou o impedimento de seis dos 22 desembargadores presentes à sessão de julgamento. Mais de um quarto dos presentes não estavam aptos a julgar, o que revela proporção alarmante capaz de levantar debate sobre a isenção do tribunal enquanto instituição pública para julgar a causa.

A Constituição, por seu turno, atribui competência ao Supremo Tribunal Federal para processar e julgar "a ação (...) em que mais da metade dos membros

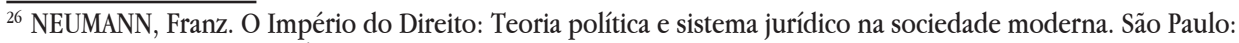
Quartier Latin, 2013, p. 69. 
do tribunal de origem estejam impedidos ou sejam direta ou indiretamente interessados" (art. 102, I, "n”). O problema está em definir se há ou não interesse direto ou indireto de mais da metade dos membros do TJRS. Tal temática não foi levada à apreciação e sequer foi suscitada por qualquer julgador. Em sede de análise crítica, importa tecer algumas considerações.

A discussão do pagamento integral da bolsa no período do feriado de 20/12/2014 a 06/01/2015 parece ser matéria de interesse direto dos magistrados em geral. Efetuar o pagamento mexe com a verba disponível para os subsídios e gratificações dos juízes e juízas, principalmente quando novos gastos começaram a ser feitos por força da generalização do auxílio-moradia. Ainda, simboliza espécie de reclamação incoerente: o grupo de trabalhadores tentou impugnar atitude da administração da entidade patronal por meio de pedido apresentado à própria entidade. A proteção corporativa tende a afastar divergências, que podem até existir isoladamente, como ocorreu com a apresentação de um único voto dissidente. Numa disputa de poder político tão desigual, na qual estagiários e estagiárias, na condição de grupo precarizado, esforçam-se para ocupar um espaço mais expressivo (ou mesmo digno) dentro da estrutura de poder dominada pelos magistrados, a via jurisdicional serviu para "autenticar" a posição política dessa classe dominante.

Processos judiciais servem para autenticar e, assim, limitar a ação política [do grupo subjugado]. [...] A autenticação remove o medo de represálias ou de liquidação de uma multidão de possíveis vítimas, e incentiva uma disposição amigável e compreensiva em relação às necessidades de segurança dos detentores do poder por parte de seus súditos. [...] Nos processos em que o público tem algum acesso, a autenticação, a regularização do extraordinário, pode, em circunstâncias favoráveis, ser transformado em uma mais profunda compreensão popular e participação política. ${ }^{27} 28$

Com o auxílio de Kirchheimer, nota-se a existência de certo uso do aparato jurisdicional a fim de reafirmar uma força política (do TJRS) em detrimento de outra (estagiários). Quando isso ocorre, a aparência tecnocrática da corte termina

\footnotetext{
${ }^{27}$ KIRCCHEIMER, Otto. Political Justice: the use of legal procedure for political ends. Princeton: Princeton University Press, 1961, p. 6-7.

${ }^{28}$ No original: Judicial proceedings serve to authenticate and thus to limit political action. (...) Authentication removes the fear of reprisals or liquidation from multitudes of possible victims, and encourages a friendly and understanding disposition toward the security needs of the power holders on the part of their subjects. [...] In proceedings in which the public has some access, authentication, the regularizing of the extraordinary, may under favorable circumstances be transformed into a deeper popular understanding and political participation.
} 
por autenticar, ou seja, conferir regularidade formal, certa posição de poder e gerar um sentimento de conformidade na sociedade. Se tal atuação já não se reveste de legitimidade democrática, ganha mais complexidade o caso em que o judiciário se autoafirma, já que Kirchheimer estava pensando na atuação judiciária perante a disputa política externa a ela. Como pode, em termos lógicos, uma corte ser sua própria instância de "autenticação"? Até para fins de aparente regularização o mecanismo se torna problemático. Advirta-se, mais uma vez, que a (falsa) legalidade ${ }^{29}$ atribuída aos atos não se confunde com a observância da forma direito. Logo, mesmo que se entenda que a legislação alberga o procedimento adotado, pode-se afigurar, na situação fática específica, condição pouco democrática de produção de norma.

Esclarecendo esquematicamente, o TJRS subordina estagiários e estagiárias por ser superior hierárquico deles e delas no vínculo que mantém, tratando-se de relação de poder típica dos contratos privados de trabalho. Também subordina a categoria com sua expressão de soberania, pois tanto regulamenta o liame como decide a respeito de sua legalidade. Onde está o espaço para a participação na esfera pública? Pode o judiciário se estruturar de tal forma a ponto de se tornar a única referência sócio-político-jurídica de si mesma? Qual o significado do acórdão proferido no MS em um cenário como esse? Essas são algumas perguntas a que se buscará elucidar na sequência.

\section{A CENTRALIDADE DO DIREITO E A NECESSIDADE DE UMA ESFERA PÚBLICA JUDICIÁRIA}

Apesar de se observarem algumas ocasiões de alto grau de instrumentalização do direito, não é negando seu potencial emancipatório que se chegará a uma integração social não violenta. Pelo contrário, experiências históricas demonstraram que a rejeição absoluta do Estado democrático de Direito burguês leva à mais perversa opressão, a políticas oficiais de extermínio, à exploração irrefreada. Kirchhei-

\footnotetext{
${ }^{29} \mathrm{Se}$, em certos momentos, faz-se uso instrumental da lei para justificar atos de poder carregados de arbitrariedade, uso esse chamado de "falsa legalidade" (RODRIGUEZ, 2009, 2015), em outras ocasióes incidem as "funções de papel" previstas na legislação. Em texto ainda inédito, esta expressão foi utilizada para designar funções previstas em texto legal (lato sensu), mas que não se efetivam na prática, não se concretizam em benefício das pessoas a quem interessa a regulamentação. É o que ocorre, por exemplo, com o objetivo do estágio gravado no art. $1^{\circ}$ da Lei n. 11788/2008 e com os deveres atribuídos às instituições frente ao estagiário e à estagiária, ambos contundentemente ignorados. Assim, falsa legalidade e funções de papel parecem ser faces da mesma moeda, ou desdobramentos da zona de autarquia, ideia a ser melhor desenvolvida em outra oportunidade.
} 
mer e Neumann produziram vários textos que mostram a necessidade de disputar o direito burguês para se chegar a uma sociedade emancipada, a ser liberada das mesmas estruturas burguesas de dominação. Se for de outro modo, regimes como nazismo, fascismo e stalinismo ganham espaço. Hodiernamente, é Habermas (2012) quem trabalha a temática ao tratar da função do direito moderno.

O direito funciona como uma espécie de transformador, o qual impede, em primeiro lugar, que a rede geral da comunicação, socialmente integradora, se rompa. Mensagens normativas só conseguem circular em toda a amplidão da sociedade através da linguagem do direito; sem a tradução para o código do direito, que é complexo, porém aberto tanto ao mundo da vida quanto ao sistema, estes não encontrariam eco nos universos de ação dirigidos por meios. ${ }^{30}$

Dado que a positivação do direito resulta da racionalização de suas bases de validade, o direito moderno conseguirá estabilizar as expectativas de comportamento de uma sociedade complexa, que inclui mundos da vida estruturalmente diferenciados e subsistemas funcionalmente independentes $\left[\ldots . .{ }^{31}\right.$

Nessa esteira, o direito assume papel central na mediação de interesses, necessidades e forças sociais, permitindo a contenção de outros mecanismos de intercâmbio social como o dinheiro e o poder administrativo. Aposta-se, pois, no direito para a manutenção da "rede geral de comunicação" e para a estabilização das expectativas de comportamento. Torna-se elemento fundamental de uma dinâmica social pretensamente emancipada, sem descuidar, é claro, de outras instituições sociais igualmente importantes, como a moral, a religião, a ciência, o sistema de comunicação etc.

Como bem aborda Rodriguez, "se o direito é mediação necessária para a emancipação humana, a tarefa da teoria crítica é defender uma práxis que se dirija para a construção de instituições inclusivas, que favoreçam o controle social da regulação"32, ideia complementada com a consideração de que "uma crítica mais abrangente deve questionar a centralidade do Judiciário para o direito"33. Neste último aspecto, Habermas parece seguir por outra via. Resguarda à legislação o polo por

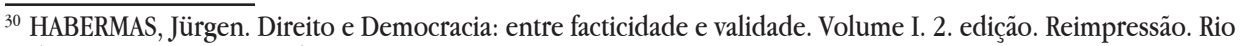
de Janeiro: Tempo Brasileiro, 2012, p. 82.

${ }^{31}$ HABERMAS, Jürgen. Direito e Democracia: entre facticidade e validade. Volume I. 2. edição. Reimpressão. Rio de Janeiro: Tempo Brasileiro, 2012, p. 105.

${ }^{32}$ RODRIGUEZ, José Rodrigo. Fuga do direito: um estudo sobre o direito contemporâneo a partir de Franz Neumann. São Paulo: Saraiva, 2009, p. 129.

${ }^{33}$ RODRIGUEZ, José Rodrigo. Como decidem as cortes?: para uma crítica do direito (brasileiro). Rio de Janeiro: FGV, 2013, p. 13.
} 
excelência da legitimidade do sistema jurídico, guardando aos tribunais a posição de agentes independentes "que decidem autoritária e imparcialmente os casos de disputa no quadro das leis" ${ }^{\text {. }}$. Assim, negligencia a formulação de uma esfera pública mais ampla e discursiva no âmbito do poder judiciário, ao presumir que a lei, observando os princípios de sua teoria do discurso, carregaria integralmente o aspecto democrático do direito.

Se Habermas estivesse certo, a jurisdição seria provocada marginalmente, tendo em vista a consideração recíproca de direitos pelas pessoas que integram uma comunidade, bem como a formulação de políticas e regulações segundo preceitos de um "espaço ideal de fala". No entanto, o cenário atual de violação de direitos, donde o Estado sobressai como maior réu em ações judiciais ${ }^{35}$, e o elevado grau de desagregação social fruto, dentre outros fatores, do crescimento da zona do precariado, redunda no aumento constante da judicialização de demandas, no que já se denomina "judicialização da política" e até "judicialização da vida". O volume de processos não para de crescer e o judiciário não tem correspondido a contento. Para citar apenas o ano de 2014, o TJRS (segundo dados próprios) teve iniciados, no primeiro e segundo graus, 2.345 .852 novos processos, finalizando 2.117 .481 processos, o que, somando-se aos processos em trâmite desde anos anteriores, produz uma pendência de 4.201.702 processos.

Esse é também o quadro nacional (em todas as esferas e graus de jurisdição), já que, conforme dados do Conselho Nacional de Justiça (através do programa Justiça em Números), em 2014 houve defasagem de $0,5 \%$ entre processos iniciados e concluídos, ultrapassando 71,2 milhões de processos pendentes e levando a Taxa de Congestionamento do Poder Judiciário ${ }^{36}$ a $71,4 \%$, com aumento de $0,8 \%$. Tudo indica, enfim, que Habermas não se preocupou em resolver o fenômeno urgente da judicialização.

O deslocamento de pressão por direitos para o judiciário não recebeu a devida atenção, o que sugere a presente discussão sobre uma esfera pública judiciária. Isso não quer dizer que ele blindou o judiciário de críticas, mas parece ter reduzido

\footnotetext{
${ }^{34}$ HABERMAS, Jürgen. Direito e Democracia: entre facticidade e validade. Volume I. 2. edição. Reimpressão. Rio de Janeiro: Tempo Brasileiro, 2012, p. 162.

35 Ver JOTA, 2015; CONJUR, 2012.

${ }^{36} \mathrm{O}$ CNJ chama de Taxa de Congestionamento o "indicador que compara o que não foi baixado com o que tramitou durante o ano-base (soma dos casos novos e dos casos pendentes iniciais)", ou seja, é o índice que mede o acúmulo de processos em tramitação, de modo que para cada 100 novos processos menos de 30 são baixados. O ideal seria que a Taxa estivesse em zero, pois todos os processos iniciados seriam concluídos no mesmo ano.
} 
a possibilidade de criticar a observância ou não da lei e a independência em relação ao executivo, o que reduz o papel da jurisdição ao se aproximar da concepção de judiciário própria da tripartição clássica de poderes.

Por outro ângulo, Habermas descreve esfera pública como "uma rede adequada para a comunicação de conteúdos, tomadas de posição e opiniões; nela os fluxos comunicacionais são filtrados e sintetizados, a ponto de se condensarem em opiniões públicas enfeixadas em temas específicos” (2011, p. 93). O teórico alemão estudou as nuances da esfera pública em vários trabalhos, sendo destacável aquele específico para a matéria, intitulado "Mudança estrutural da esfera pública" (2003). Sua tentativa é a de mostrar como a sociedade burguesa criou um espaço público destinado à política e voltado a garantir liberdades e separar o espectro de atuação do Estado da sociedade civil. Diante das contradições admitidas nos debates da esfera pública, aponta-se o potencial emancipatório dessa formulação, desde que mediada pelo direito e orientada por um agir comunicativo ${ }^{37}$.

O judiciário não escapa a essa razão de ser. Sua manifestação aparentemente técnica precisa estar submetida à efetiva participação popular (não só das partes em litígio) e ao controle social. Aqui não há espaço para a propositura de mecanismos e institucionalidades desse tipo, posto demandar reflexões mais alentadas. Será realizada exclusivamente a defesa de um espaço público que inclua a jurisdição. $\mathrm{O}$ aporte constitucional existente dá margem a uma construção nesse sentido. A atribuição de sentido à ordem republicana, democrática, solidária e cujo poder emana do povo, conforme preceitua a Lei Maior, permite o entendimento de que o judiciário, enquanto esfera de concentração e distribuição do poder, deve sujeitar-se a controles que não exclusivamente autorreferentes.

Os limites da autorreferência judicial são claramente visualizáveis no caso dos estagiários e das estagiárias do TJRS. Foi negada a participação destes na definição administrativa do modo de remuneração, o que já apresenta um primeiro fechamento da estrutura. Faltou órgão externo ao judiciário para socorrer esses trabalhadores, representando segundo obstáculo à participação democrática. O processo judicial, tramitado de acordo com o modelo processual individualista vigente, também não dispôs de ferramentas que fizessem dos estagiários protagonistas da resolução do problema. O Procurador Geral do Estado, intimado para se manifestar, deixou transcorrer o prazo sem falar nos autos, anunciando a pouca relevância que

${ }^{37}$ Muito rasamente, pode-se dizer que o agir comunicativo é aquele agir voltado ao entendimento coletivo com vistas à formação de consensos racionais. Ver Habermas, 2010. 
o poder estatal atribuiu à questão. Por óbvio, instaurou-se uma correlação de forças deveras desigual, a instigar, como comportamento crítico, tentativas de reformular essa modus operandi institucional.

Ademais, as cortes de justiça têm a função de conter atos dos demais poderes, notadamente quanto ao controle de constitucionalidade e legalidade, muitas vezes protegendo interesses contra-hegemônicos. Porém, a contenção de seus próprios atos é pouco eficaz, preocupação constante para muitos estudiosos, como foi o caso de Neumann, que ponderou: "como acontece em todo caso de controle de um órgão do Estado por meio de outro, sempre surge a questão: quem controla os controladores?"38. Já Kirchheimer (1961), percebendo as influências externas a que os julgadores estão submetidas, fez vasta análise do uso dos procedimentos judiciais como forma de afirmar/reforçar posições políticas de um grupo em relação a outro(s). Considerou ele que em todos os regimes de governo, englobando os constitucionais-democráticos, há, em maior ou menor grau, esse direcionamento da justiça na perseguição de fins políticos.

Diante da situação narrada, como controlar a jurisdição e racionalizar as diversas influências a que se sujeita o judiciário? Como dito alhures, aposta-se na inclusão desse poder constituído numa esfera pública desenhada para garantir "a participação no produto social e nas instituições da esfera pública política" ${ }^{\text {", }}$, empenhando esforços para que essa participação seja ampliada e tornada efetiva. Para começar, é indispensável a publicidade das informações para não subverter a esfera pública e oferecer iguais condições de participação às forças em disputa.

O TJRS, quando do contato com estagiários e estagiárias, omitiu informações que afetavam diretamente a categoria. Não deu conhecimento do meio usado para que se chegasse ao corte da bolsa. Quando o $3^{\circ}$ vice-presidente prestou informações no mandado de segurança $n$. 70062879986, trouxe à baila fatos de total desconhecimento da categoria reivindicante. Mesmo assim, não foi oportunizada manifestação por parte dos impetrantes. Mais grave ainda foi a consideração, nos fundamentos da decisão, de uma suposta notícia levado ao TJRS pelo TCE por vias informais. Ao passo em que era defendida uma legalidade estrita para confirmar a posição do TJ de que não havia previsão legal a respaldar o pagamento, essa mesma

\footnotetext{
${ }^{38}$ NEUMANN, Franz. O Império do Direito: Teoria política e sistema jurídico na sociedade moderna. São Paulo: Quartier Latin, 2013, p. 131.

${ }^{39}$ HABERMAS, Jürgen. Mudança estrutural da Esfera Pública: investigações quanto a uma categoria da sociedade burguesa. Rio de Janeiro: Tempo Brasileiro, 2003, p. 268.
} 
legalidade foi ignorada quanto à vinculação do poder público à oficialidade dos atos. Elementos básicos de uma esfera pública constitucionalizada foram violados.

A fixação constitucional de uma esfera pública politicamente atuante revela mais só no artigo central (que afirma que todo o poder emana do povo) o caráter de uma ordem de dominação conseguida mesmo através do poder com muito esforço. No mais, o Estado de Direito burguês pretende, à base da esfera pública em funcionamento, uma organização às exigências de uma esfera privada que se pretende neutralizada quanto ao poder e emancipada quanto à dominação. As normas constitucionais são, com isso, fundadas num modelo de sociedade civil burguesa a cuja realidade elas não correspondem de jeito nenhum..$^{40}$

A esfera pública, sempre sujeita a pressões para subvertê-la, tanto pode guiar-se pelos princípios e regras constitucionais que fazem dela uma rede comunicativa com potencial emancipatório como pode ir se esfacelando pelo poder pouco controlado de algum dos entes. Como o judiciário não observa contenções eficazes, acaba por dominar o espaço destinado à liberdade do público envolvido. De tão central para o atual modelo de resolução de conflitos, o bloqueio contra a participação mais ampla justifica o qualificativo de que o judiciário é uma "caixa-preta": "O normativismo próprio das noções de 'judicialização da política' e de 'ativismo judicial' vê o espaço jurisdicional como infenso à política em sentido amplo, o que corresponde ao preconceito mais geral de que o Judiciário como instituição é uma 'caixa-preta'." 11 .

Isso não quer dizer que se deve naturalizar a judicialização. É necessário compatibilizar o estado atual de litigância com outros métodos de institucionalização de demandas, mas conscientes da necessidade de disputar o espaço judicial atualmente à disposição da sociedade. Não há contexto para abandono repentino do modelo vigente, já que a cultura tem se firmado no sentido de concentrar no judiciário a solução de conflitos. Também não é o caso de negar a estrutura disponível, pois, como já visto, rejeitar tout court o Estado democrático de Direito burguês geralmente abre margem a governos de exceção. Assim, na medida em que o sistema de justiça deve ser questionado, novas práticas precisam ser estimuladas, até atingir, quem sabe, propostas como a de Warat de uma justiça constituída a partir da ideia

\footnotetext{
${ }^{40}$ HABERMAS, Jürgen. Mudança estrutural da Esfera Pública: investigações quanto a uma categoria da sociedade burguesa. Rio de Janeiro: Tempo Brasileiro, 2003, p. 104.

${ }^{41}$ RODRIGUEZ, José Rodrigo. Como decidem as cortes?: para uma crítica do direito (brasileiro). Rio de Janeiro: FGV, 2013, p. 189.
} 
de "mediação do excluído" ‘2. Enquanto isso, reconhecimentos de direitos pelas vias formais podem ser reconhecimentos, a exemplo do voto divergente no MS em análise, da lavra do desembargador Sylvio Baptista Neto,

Com efeito, não é possível, como parte concedente (art. $9^{\circ}$ da Lei $\mathrm{n}^{\mathrm{o}}$ 11.788/2008), ao Poder Judiciário, unilateralmente, suspender o estágio, ou o pagamento da bolsa de contraprestação, como se fosse parte única nesta relação em que há, ao menos, três partes: o TJRS, a Universidade em decorrência do convênio celebrado, e o estagiário. (...)

Não é possível conceber um retrocesso de tal natureza como o que está ocorrendo - que o TJRS deixe de pagar a bolsa de contraprestação aos estagiários só pelo fato de entrar em recesso por alguns dias no final do ano, no período entre 20 de dezembro e 6 de janeiro.

Insta acentuar que os estagiários - muitos deles - dependem dessa pequena quantia para fazer frente às suas necessidades e, especialmente na época do final do ano, em que avultam as despesas natalinas. Pode-se dizer que é incompreensível, mesmo, deixar de pagar essa bolsa de contraprestacão aos estagiários.

(...)

Convém dizer ainda algo sobre a relação trabalho x capital. Em recente artigo publicado no Jornal Zero Hora, a Juíza do Trabalho Valdete Souto Severo assim tratou da Medida Provisória n ${ }^{\circ} 680$ que trata do Programa de Proteção ao Emprego:

MENTIRA PROGRAMADA:

A MP 680 institui um "Programa de Proteção ao Emprego", mas em realidade reproduz uma tática antiga do capital, traduzida por Marx no seguinte trecho de seus Manuscritos: "Se a riqueza da sociedade estiver em declínio, então o trabalhador sofre ao máximo, pois: ainda que a classe trabalhadora não possa ganhar tanto quanto a classe dos proprietários na situação próspera da sociedade, nenhuma sofre tão cruelmente com o seu declínio como a classe dos trabalhadores". Em recente reportagem, empregados foram entrevistados para dizer o quanto sentiam-se felizes por estarem em "lay off", pois pelo menos não haviam sido "desligados". A perversão do capital atinge requintes de crueldade. Imputa-se ao explorado a responsabilidade por sua própria exploração, exigindolhe sacrifícios que permitam prosseguir em sua condição de sujeição. Ao mesmo tempo, exalta-se a sua capacidade de adaptação, e o trabalhador, vivendo a síndrome de Estocolmo, agradece comovido ao Estado e ao empregador, que lhe garantem, como agentes simbióticos de reprodução dessa lógica, a possibilidade de continuar sendo usurpado em seus direitos básicos.

(...)

${ }^{42}$ Ver Warat, 2004. 
O mesmo é válido para a relação entre o estagiário, a Instituição de Ensino e, no caso, o Poder Judiciário. Os estagiários constituem fonte de trabalho que, atualmente, se constata, indispensável e valiosa. Todavia, quando o judiciário impõe a redução de dias de trabalho por conta de um recesso anual de final de ano, deixam de remunerar os estagiários, como se eles pudessem ser contrários e como se eles não pudessem ser tratados da mesma forma como são tratados os demais servidores do Judiciário.

Enfim, não é preciso dizer mais.

Voto, portanto, pela rejeição da preliminar de ilegitimidade e pela concessão da segurança, com vistas a anular o ato que determinou a suspensão do pagamento da bolsa de contraprestação do estágio no período de recesso.

Essa longa citação à posição dissidente é necessária para demonstrar a viabilidade de formular pensamentos críticos mesmo dentro da institucionalidade atual. O desembargador considerou inadmissível a conduta contestada. Imputou a impossibilidade de suspensão do pagamento durante o "recesso" a partir de posição unilateral do TJRS, o qual desconsiderou a instituição de ensino e os estagiários. Esse pensar está em plena conformidade com a formulação habermasiana de necessidade de participação dos sujeitos afetadas nas políticas que lhes digam respeito (2010), sob pena de ser considerada ilegítima.

Os afetados, no caso, foram os estagiários e as estagiárias, que tiveram prejuízos econômicos, com lesão a direitos fundamentais por perda parcial da capacidade de atender às necessidades pessoais. $\mathrm{O}$ magistrado ainda teceu comentários relevantes quanto à relação capital $\mathrm{x}$ trabalho, ao transcrever matéria publicada por uma juíza do trabalho e destacar a perversidade de um estado que "imputa ao explorado a responsabilidade pela própria exploração". Desse modo, fez importante referência à posição do polo litigante enquanto mão de obra explorada, ou, nos termos aqui adotados, trabalhadores precariados. Por fim, referiu-se à impossibilidade de escolha dos estagiários frente à adoção do feriado (que logicamente gerou dias não trabalhados), mas que mesmo assim fez com que não fossem "tratados da mesma forma como são tratados os demais servidores do Judiciário".

O desembargador mostrou, em síntese, que a esfera pública estava sendo tomada por determinações arbitrárias, totalmente na contramão dos debates exigidos numa ordem jurídica efetivamente democrática. Critérios discriminatórios e excludentes foram utilizados, sem a menor preocupação em racionalizar a justificativa da decisão. Se, segundo a forma direito, o TJRS estivesse autorizado a negar direitos 
a um grupo de trabalhadores em detrimento dos demais, direitos humanos e fundamentais seriam dispensáveis à ordem jurídica, já que algumas pessoas podem ser consideradas menos dignas ou menos cidadãs.

Existe uma realidade judiciária que não pode ser desprezada. As pessoas têm provocado o sistema de justiça para satisfazer interesses e necessidades, apesar de tratá-lo com desconfiança. A mediação via direito não pode se afastar desse problema. Na contenda delineada pelo mandado de segurança n. 70062879986, não se formou "uma rede adequada para a comunicação de conteúdos, tomadas de posição e opiniões", já que tanto a escolha administrativa quanto o acórdão estiveram alicerçados em posições autárquicas, unilaterais. Todavia, se o judiciário é uma via amplamente acessada, precisa sofrer reformulações e submeter sua estrutura à transparência, sem falar nas críticas à razão de decidir, como meio eficaz de transformação social rumo a vínculos de integração mais solidários.

\section{CONCLUSÃO}

O pensamento crítico requer o emprego de esforços para analisar a conjuntura dos laços sociais existentes, buscando levar em conta os mais diversos aspectos da vida. Na complexa, plural e problemática organização social do mundo globalizado, o direito desponta como elemento cujas contradições carecem de maiores estudos voltados ao desenvolvimento de práticas tendentes a liberar os potenciais emancipatórios em estado de latência. Isso porque, até agora, mostrou ser o melhor meio de integrar a sociedade com níveis razoáveis de controle sobre a violência e a exploração.

Para viabilizar a generalização e a ampliação da forma direito nas instituições sociais, investigar as práticas judiciárias torna-se um imperativo prioritário na ordem do dia. Por isso, escolheu-se apreciar caso de disputa de interesses entre um tribunal pátrio (o TJRS) e uma categoria de trabalhadores a ele vinculada (a de estagiários e de estagiárias). O que se observou foi a confusão entre as três funções tradicionais do Estado: o TJ emitiu regramento (dias de recesso), administrou (decidiu não pagar) e julgou a contenda oriunda do ato (mandado de segurança). Faltou, portanto, a formulação de arranjos institucionais que favoreçam o controle social da regulação. 
De igual maneira, a decisão lançada pela corte seguiu a "lógica do parecer", não construindo uma argumentação racional em sentido material (nem mesmo em sentido formal). Uma decisão judicial poderia ser tida como uma atividade de pesquisa circunscrita num aparato institucional democrático, o qual leva em conta a posição dos afetados. Nessa fórmula, o julgador atuaria não pessoalizando uma "convicção", mas argumentando de acordo com os aportes jurídicos envolvidos no caso em tela. Contudo, em sentido contrário, reforçaram uma jurisdição personalista ${ }^{43}$, escolheram previamente o resultado "pareceristicamente" ${ }^{44} \mathrm{e}$, a pretexto de análise "técnica", restringiram direitos dos estagiários.

Houve uma distribuição desigual do poder entre as forças sociais envolvidas. O judiciário autenticou seu poderio privilegiado e outorgou aos estagiários e às estagiárias o rótulo oficial de sujeitos do precariado formalmente reconhecidos como discriminados no acesso a direitos fundamentais, menos cidadãos e menos dignos de reconhecimento institucional. Em que pese a existência de dados oficiais informando o grande impacto da mão de obra desses trabalhadores na força de trabalho do TJRS (e do judiciário brasileiro como um todo), no momento de atribuir direitos prefere-se caracterizar o vínculo existente entre as partes como de exclusiva aprendizagem, o mesmo não ocorrendo quando da inobservância dos deveres legais de acompanhamento das atividades de estágio.

As situações visualizadas apontaram, então, modos de ser das zonas de autarquia e usos da falsa legalidade. Ainda assim, o que importa frisar é a necessidade de reforço à disputa pela formação de esferas públicas democráticas, e não o abandono do Império do Direito. O debate público regulado democraticamente permite que posições até agora contra-hegemônicas sejam defendidas em nome da emancipação social. A "luta por direitos na democracia" é a chave para evitar retrocessos. É a fórmula mais eficaz de buscar o efetivo controle dos poderes político e econômico, a transparência da atuação estatal e a ampla participação no desenvolvimento de políticas, sobretudo com consideração às necessidades dos sujeitos afetados.

\section{REFERÊNCIAS}

BRAGA, Ruy. A política do precariado: do populismo à hegemonia lulista. São Paulo: Boitempo/Programa de Pós Graduação em Sociologia - USP, 2012.

\footnotetext{
$\overline{43}$ Ver RODRIGUEZ, 2013.

${ }^{44}$ Ver NOBRE, 2003.
} 
CONSELHO NACIONAL DE JUSTIÇA. Justiça em números 2015: ano-base 2014. Brasília: CNJ, 2015.

CONSULTOR JURÍDICO. INSS é órgão recordista de processos em $1^{\mathrm{a}}$ Instância. Publicado em 04 nov. 2012. Disponível em: < http://www.conjur.com.br/2012-nov-04/ inss-municipios-estados-lideram-lista-grandes-litigantes-cnj $>$. Acesso em: $10 \mathrm{fev}$. 2016.

FARIA, José Eduardo. Direito e Justiça: a função social do judiciário. São Paulo: Editora Ática, 1997.

HABERMAS, Jürgen. Direito e Democracia: entre facticidade e validade. Volume I. 2. edição. Reimpressão. Rio de Janeiro: Tempo Brasileiro, 2012.

HABERMAS, Jürgen. Direito e Democracia: entre facticidade e validade. Volume II. 2. edição. Rio de Janeiro: Tempo Brasileiro, 2011.

HABERMAS, Jürgen. Mudança estrutural da Esfera Pública: investigações quanto a uma categoria da sociedade burguesa. Rio de Janeiro: Tempo Brasileiro, 2003.

HABERMAS, Jürgen. Teoría de la acción comunicativa. Volume único. Madrid: Editorial Trotta, 2010.

JOTA. AMB mostra quem são os maiores litigantes do país. Publicado em 11 ago. 2015. Disponível em: < http://jota.uol.com.br/amb-mostra-quem-sao-os-maiores-litigantes-pais > . Acesso em: 10 fev. 2016.

KIRCCHEIMER, Otto. Political Justice: the use of legal procedure for political ends. Princeton: Princeton University Press, 1961.

MARTINS, Sérgio Pinto. Direito do trabalho. 28. edição. São Paulo: Editora Atlas, 2012.

MICHAELIS DICIONÁRIO DE PORTUGUÊS ONLINE. Feriado. Disponível em: $<$ http://michaelis.uol.com.br/moderno/portugues/index.php?lingua = portugues-portugues\&palavra =feriado $>$. Acesso em: 10 fev. 2016. 
NEUMANN, Franz. O Império do Direito: Teoria política e sistema jurídico na sociedade moderna. São Paulo: Quartier Latin, 2013.

NOBRE, Marcos. Apontamentos sobre a pesquisa em direito no Brasil. Novos Estudos, número 66, p. 145-154, julho de 2003. Disponível em: < http://novosestudos. uol.com.br/v1/contents/view/1079> . Acesso em: 21 jan. 2016.

NOBRE, Marcos. Introdução. In: NOBRE, Marcos. Curso livre de Teoria Crítica. 3. edição. 2. reimpressão. Campinas: Papirus, 2015.

RODRIGUEZ, José Rodrigo. Como decidem as cortes?: para uma crítica do direito (brasileiro). Rio de Janeiro: FGV, 2013.

RODRIGUEZ, José Rodrigo. Fuga do direito: um estudo sobre o direito contemporâneo a partir de Franz Neumann. São Paulo: Saraiva, 2009.

RODRIGUEZ, José Rodrigo. Luta por direitos, rebeliões e democracia no século XXI: algumas tarefas para a pesquisa em direito. In: STRECK, Lenio Luiz; ROCHA, Leonel Severo; ENGELMANN, Wilson. Constituição, Sistemas Sociais e Hermenêutica: anuário do programa de Pós-Graduação em Direito da UNISINOS: Mestrado e Doutorado. Porto Alegre: Livraria do Advogado Editora, 2014.

STANDING, Guy. O precariado: a nova classe perigosa. 1. edição. 1. reimpressão. Belo Horizonte: Autêntica Editora, 2014.

TEUBNER, Gunther. Juridificação: noções, características, limites, soluções. Revista de Direito e Economia, número 14, Ano XIV, p. 14-100, 1988.

TRIBUNAL DE JUSTIÇA DO RIO GRANDE DO SUL. Disponível em: < http://transparencia.tjrs.jus.br/forca_trabalho/index.php> Acesso em: 23 abr. 2015

TRIBUNAL DE JUSTIÇA DO RIO GRANDE DO SUL. Disponível em: < http://transparencia.tjrs.jus.br/dados_juris/demanda_produtividade.php $>$ Acesso em: 24 abr. 2015

WARAT, Luis Alberto. Surfando na Pororoca: o ofício do mediador. Florianópolis: Fundação Boiteux, 2004. 
Recebido em: 02 de julbo de 2016

Aceito em: 24 de julbo de 2018 